\title{
Historical surveys reveal a long-term decline in muskrat populations
}

\author{
Carrie Sadowski ${ }^{1}$ and Jeff Bowman ${ }^{1}$ \\ ${ }^{1}$ Ontario Ministry of Natural Resources and Forestry
}

January 6, 2021

\begin{abstract}
The muskrat (Ondatra zibethicus) is an iconic species in Canada, valued for both its fur and its integral role in wetland ecosystems, and widely regarded for its perseverance. However, the resilience of this semi-aquatic mammal seems to be in question now as increasing evidence points to widespread population declines. Recent analyses of harvest data across North America suggest a reduction in their numbers, but this has not been widely corroborated by population surveys. In this study we replicated historic muskrat house count surveys at two large Great Lakes coastal wetlands and present confirmation that declines in muskrat harvest correspond to actual declines in muskrat abundance. At the Point Pelee National Park marsh and the Matchedash Bay-Gray Marsh wetland we found that mean muskrat house counts declined by $93 \%$ and $91 \%$ respectively between historic surveys 40-50 years ago and contemporary surveys over the past five years. The factors responsible for these dramatic declines remain unclear but there may be a relationship with changes in the habitat quality of these wetlands that have occurred over the same time frame. Not only is the loss of muskrats an issue for the resulting loss of the wetland ecosystem services they provide, but it may be an indication of broader marsh ecosystem degradation. As such, a scarcity of muskrats should be considered a red flag for the state of biodiversity in our wetlands. Continued surveys and ongoing research are needed to shed more light on the current status of muskrat populations and their marsh habitats across their native range. Keywords: Fur harvest; Muskrat; Ondatra; Population decline; Typha; Wetlands
\end{abstract}

\section{Introduction}

The muskrat (Ondatra zibethicus) is seen as a fixture of wetlands across North America, being one of the most common and widely distributed furbearer species on the continent. They are found primarily in marshes, but also in ponds, sloughs, lakes, ditches, rivers and streams from the east coast to the west, and from the Mackenzie Delta in Canada's north to northern Mexico in the south (Boutin and Birkenholz, 1987). The muskrat also ranks as the most heavily harvested wild furbearer in North America of the 20th century (Obbard et al., 1987) and has contributed more than any other animal to the combined income of North America's trappers over the past 150 years (OFMF, 2019). In the early 1900s, millions of muskrats were trapped and sold across North America and, though harvest numbers are lower today, muskrats remain a major source of income for fur trappers and are still among the most prevalent species trapped for fur (Fur Institute of Canada, 2019).

While the muskrat played a major role in the early fur trade and colonization of North America by Europeans (White et al., 2015), the species has been of cultural significance as a traditional clothing and food item and as a spiritual symbol among Indigenous people long before European explorers arrived on the continent. For example, in an Anishinaabe story of creation, the muskrat (Wa-zhushk) comes to the rescue to help re-build the Earth after a great flood and decimation of life, and is said to embody humility, courage, and determination (MacGregor, 2013).

As a wetland obligate and dominant herbivore, the muskrat plays several important roles in wetland ecosystems. Their foraging, travel, and house-building activities create numerous small openings in marsh vegetation, thereby increasing the interspersion of open water and emergent vegetation which often results in 
increased structural diversity and plant species richness in wetlands (Nyman et al., 1993; Connors et al., 2000; Keddy, 2010). Different biotic communities are known to respond positively to such enhancements in habitat diversity (Wilcox and Meeker, 1992); in particular, a greater density and diversity of marsh birds and waterfowl has been found in wetlands with an equal ratio of open water to emergent vegetation (Weller and Fredrickson, 1973; Kaminski and Prince, 1981; McDonnell, 1983). Muskrat houses (both new and old) can also create important loafing and nesting sites for marsh birds. For example, the black tern (Chlidonias niger ) will use muskrat houses and feeding platforms as nesting substrate (Hickey and Malecki, 1997) and it is quite common to find Canada geese (Branta canadensis) and sometimes trumpeter swans (Cygnus buccinator ) loafing or nesting on old muskrat structures. Less recognized are the benefits that muskrats provide to snakes and turtles, many of which are species at risk. In an Illinois study, a large number of spotted turtle (Clemmys guttata) captures occurred in deep open-water pools associated with muskrat lodges where muskrat grazing decreased the vegetative cover, and it was believed that these pools served as refugia for the turtles during periods of high temperature and/or drought (Litzgus and Brooks, 2000). Numerous vertebrate species, including more than ten herptile species, have been observed using muskrat houses, burrows, cleared pathways and other features for thermoregulation, nesting, cover and ease of travel (S. Gillingwater, unpublished data; Kiviat, 1978). Furthermore, muskrat activity can influence mussel abundance (Diggins and Stewart, 2000), invertebrate communities (De Szalay and Cassidy, 2001; Nummi et al., 2006), microbial activity (Wainscott et al., 1990) and nutrient cycling (Connors et al., 2000). Muskrats are also an important food item for many predators, such as red foxes (Vulpes vulpes), coyotes (Canis latrans), raccoons (Procyon lotor ), raptors and especially mink (Neovison vison ) (McDonnell, 1983).

Early research on muskrats by Paul Errington and others illustrated the density-dependent nature of muskrat populations and a variety of abundance cycles (Errington, 1951; Clark and Kroeker, 1993; Erb et al., 2000). In their analysis of almost one hundred individual time series of muskrat harvest data from the Hudson's Bay Company in Canada, Erb et al. (2000) found that the mean period length of muskrat population cycles differed between ecozones, ranging from 3.7 to 8.6 years, with the shorter periods tending to occur at higher latitudes and in eastern regions. In some cases, however, the time series did not exhibit any periodicity. Evidence exists for both population-intrinsic factors (e.g., social factors) and extrinsic factors (e.g., disease, environmental variability and trophic interactions) explaining the observed patterns of these cycles (Errington, 1963 and Errington et al., 1963; Bulmer, 1974; Weller and Fredrickson, 1973). Despite some commonalities these patterns lack consistency across geographic areas, and in many cases muskrat population dynamics and their mechanisms of regulation remain unclear.

The muskrat is a prolific species; females typically have 2-3 litters per year and an average litter size of 6.5 kits (Boutin and Birkenholz, 1987). As well, most muskrats are able to breed the same year they are born and have high dispersal capabilities. These demographic characteristics make muskrats relatively resilient to harvest and other population pressures (e.g., disease, predation) as a small number of individuals can quickly multiply and enable population recovery. They are also reasonably flexible in their habitat requirements and, as noted by Errington (1951), muskrats often demonstrate a remarkable ability to stay alive up to the very edges of what may be considered habitable range.

Today, however, this marsh denizen may not be thriving like it once was. There is a growing body of literature suggesting declines in muskrat populations from myriad locations across North America over the past 10-20 years. Most recently Gregory et al. (2019) reported that muskrat harvest on Prince Edward Island declined by more than half when comparing the average harvest from 1977-1988 to 1988-2016. More broadly, Ahlers and Heske (2017) analyzed harvest data from 1970 to 2012 across the United States and, after controlling for pelt prices, found strong evidence that muskrat populations declined during this time period. Prior to that study, analyses by Roberts and Crimmins (2010) revealed a $75 \%$ decline in muskrat harvest across the northeastern United States and eastern Canada from 1986 to 2006. This decline was thought to be indicative of regional declines in muskrat abundance as the study's authors found that a previously strong correlation between harvest and pelt prices had weakened in the latter years of their analysis. In other words, they felt it was likely that recent changes in muskrat harvests were reflecting underlying population change (and not simply changes in harvest effort) because they did not find the strong relationship between 
harvest levels and pelt prices which had previously defined the harvest dynamics of muskrats and other furbearer populations (Scognamillo and Chamberlain, 2006; Bailey, 1981). As well, in the same study the authors reported a lack of periodic fluctuations in the modern muskrat harvest data (as compared to the historic data which exhibited mild periodicity), providing further support for widespread population decline (Roberts and Crimmins, 2010).

In Ontario, similar to trends across Canada, provincial fur harvest records show a clear decline in muskrat harvest over the past 100 years, most notably over the past 30 years (Fig. 1). In fact, the average annual number of muskrats harvested in the past 30 years has declined by more than $90 \%$ from the mean in the previous 20-year period (late 1960s to late 1980s). While some of this decline can be explained by changes in fur harvest reporting structure that occurred in Ontario in the late 1980s, as well as economic factors and cultural shifts in trapping, the magnitude and time span of the decline seems too great to be explained by these factors alone. For example, the spatial pattern of change in muskrat harvests from 1972 to 2004 suggests an actual decline in muskrat population may have occurred because the pattern did not conform to the expectation arising from spatially homogeneous decline in fur price and therefore trapper effort (Gorman 2007). Furthermore, the time span of the recent period of low muskrat harvest numbers (30 years) far exceeds that of the maximum population cycle length reported for muskrats (Erb et al., 2000). As well, the low annual numbers harvested in recent years are well below the lower limit of published historic muskrat population fluctuations (Statistics Canada, 2011).

Since many furbearers (including muskrats) are difficult and costly to census (Erb and Perry, 2003), harvest data are often the only type of information related to species' population trends that are available for a long time series or across a large geographic area (White et al., 2015). However, there are problems with relying on harvest data to infer wildlife population trends, and these have been noted by many of the same authors that have analyzed harvest trends of furbearers (e.g., Gregory, 2019; Roberts and Crimmins, 2010). For example, harvest data can encompass trapping seasons of different lengths, can be missing data for some years, or can be deficient due to lack of full reporting. More importantly, harvest data can be biased by trapping effort which can be affected by the number of trappers or by changing economic factors (e.g., pelt price) that may encourage or discourage trappers (Landholt and Genoways, 2000).

Although long-term census data on muskrat populations are generally rare, a few researchers have published evidence of declines in local muskrat populations from direct count surveys. For example, Benoit and Askins (1999) reported that counts of muskrat houses from marshes of the Quinnipiac and Connecticut Rivers decreased dramatically (78\% and 100\% respectively) between 1965 and 1990. As well, Ward and Gorelick (2018) analyzed muskrat house count records from 1970 to 2016 for the Peace-Athabasca Delta in Canada and found a significant decline in population density over this time frame.

Other recent studies, while not long-term in nature, have reported finding lower than expected muskrat densities in areas of seemingly suitable habitat. For example, Toner et al. (2010) reported a mean muskrat density of 0.71 houses/ha in six coastal wetlands along the Upper St. Lawrence River surveyed multiple times from 2001 to 2006, and Greenhorn et al. (2017) found a mean muskrat density of 0.27 houses/ha in 43 cattail-dominated marshes surveyed along the north shore of Lake Ontario in 2014. In 2009, Gregory et al. (2019) intensively searched four marshes on Prince Edward Island for muskrats and reported a mean density of just 0.07 houses/ha. All of these results are much lower than the typical densities of $2.1-3.6$ muskrat houses/ha reported previously in the literature for cattail-dominated marshes in Canada (Proulx and Gilbert, 1984; Messier and Virgil, 1992).

Anecdotal and interview-based reports of muskrat decline over the past few decades have also been reported by trappers (Gregory et al., 2019), fur managers (Roberts and Crimmins, 2010) and Indigenous people across Canada (Brietzke, 2015; Straka et al., 2018; S. Mallany, personal communication, December 2016), and have also been received from a variety of sources by us. The underlying theme among these reports is that trappers and other long-term land users are simply not finding muskrats in the numbers they used to, despite efforts to do so. 
Collectively these recent studies and reports point to potential widespread declines in muskrat populations. However, robust empirical data on long-term trends in muskrat populations based on field observations are generally scarce in the literature. Thus, more information is needed to confirm that declines in muskrat harvest correspond to real declines in muskrat abundance (Ahlers and Heske, 2017). Fortunately, we learned of annual muskrat field surveys having been conducted at multiple locations in Ontario, Canada between 1950 and 1990 and sought to exploit this untapped source of historic muskrat population data.

Our specific objectives in this study were to locate and revisit sites where historic muskrat survey data exists for Ontario, to replicate the historic survey methods as closely as possible, and to then compare contemporary survey results with the historic data to determine if there have been empirical changes in the muskrat populations in these areas. We hypothesized that declines observed in muskrat harvest are due at least in part to real declines in muskrat populations. Therefore, we expected to observe evidence of fewer muskrats in contemporary versus historic muskrat surveys.

\section{Methods}

\subsection{Study Area}

We found two sites in Ontario with collections of multi-year historic muskrat survey data from coastal wetlands: Point Pelee National Park and Matchedash Bay-Gray Marsh (Fig. 2). In both cases the historic data were more than 30 years old. The methods and data from these surveys are published in internal government reports and we were able to obtain copies from the respective offices responsible for the resource management of these sites. We replicated the historic muskrat surveys in the marshes of these two locations between 2014 and 2019. Both sites are considered Great Lakes coastal wetlands but are of different hydrogeomorphic types; the Point Pelee marsh is classified as a barrier-beach wetland while the Matchedash Bay complex is classified as a combination of protected embayment and drowned river mouth wetlands (Albert et al., 2005). These two sites are situated on different Great Lakes and are separated geographically by a straight-line distance of $385 \mathrm{~km}$.

\subsubsection{Point Pelee Marsh}

The Point Pelee marsh $\left(41^{\circ} 57^{\prime} \mathrm{N}, 82^{\circ} 31^{\prime} \mathrm{W}\right.$; hereafter Pelee) occurs within a sandspit peninsula located on the north side of Lake Erie at the southern-most tip of Canada's mainland in the Carolinian forest zone (Lake Erie-Lake Ontario Ecoregion) of the Mixedwood Plains Ecozone (Crins et al., 2009). The marsh is approximately 1100 ha in surface area (including large open water areas) and is designated as both a Provincially Significant Wetland in Ontario (MNRF, 2015) and a RAMSAR Wetland of International Significance by UNESCO. It is a protected area situated in Canada's smallest national park which experiences over 200,000 visitors each year (Parks Canada, 2010). Muskrat trapping was historically a popular activity in the Pelee marsh but has not occurred there since 1958 when Parks Canada prohibited all trapping within the National Park (Menefy, 1969).

\subsubsection{Matchedash Bay-Gray Marsh}

The Matchedash Bay and Gray Marsh wetland complex $\left(44^{\circ} 45^{\prime} \mathrm{N}, 79^{\circ} 40^{\prime} \mathrm{W}\right.$; hereafter Matchedash) is located in central Ontario near the southeastern end of Lake Huron's Georgian Bay, spanning the boundary of the Georgian Bay and Lake Simcoe-Rideau Ecoregions at the interface of the Mixedwood Plains and Ontario Shield Ecozones (Crins et al., 2009). Similar to the Pelee wetland, the Matchedash wetland is approximately 1100 ha in surface area (including large open water areas) and is designated as both a Provincially Significant Wetland in Ontario (MNRF, 2015) and a RAMSAR Wetland of International Significance by UNESCO (Wilson and Cheskey, 2001). Matchedash is primarily Crown Land (much of it designated and protected as a Provincial Wildlife Area), but there are several parcels owned and managed by Ducks Unlimited Canada under the Eastern Habitat Joint Venture project (Ducks Unlimited, 2011). Licensed trapping is permitted and occurs throughout the wetland.

Both wetlands consist of approximately 700 ha of robust emergent marsh vegetation (MNRF, 2015) which is considered to be suitable muskrat habitat (Bellrose and Brown, 1941; Clark, 1994; Proulx and Gilbert, 
1983). Cattails (Typha spp.) are by far the dominant plant species at both sites, comprising $89 \%$ of the marsh vegetation at Pelee (Markle et al., 2018) and representing the most common wetland cover type at Matchedash (Gartner Lee Limited, 1990). The invasive European common reed (Phragmites australis ssp. australis $)$ is also present in each marsh $(\sim 6.5 \%$ of the marsh vegetation at Pelee; unknown coverage at Matchedash), along with relatively low coverage by narrow-leaved emergents, forb marsh and graminoid meadow marsh community types (Markle et al., 2018; Gartner Lee Limited, 1990; Sadowski pers. obs.).

\subsection{Survey Methods}

We aimed to replicate the historic survey methods as closely as possible to obtain comparable contemporary results. We undertook this task by following the detailed descriptions and survey maps provided in the old reports to re-locate the same survey areas for each site. At Point Pelee National Park, muskrat surveys were initiated in the 1950s by Parks Canada staff and standardized in 1963 when the marsh was divided into 14 survey zones, with a $15^{\text {th }}$ zone added in 1971 (Reive, 1978). The zones remained consistent in subsequent years; however, a few boundary adjustments were made in 1979 to accommodate changes in the vegetation structure of the marsh (Reive, 1979). The surveys were conducted annually until 1980, after which time no further muskrat surveys were undertaken (Bremner and Reive, 1980). At Matchedash Bay-Gray Marsh, muskrat surveys were initiated in late fall 1978 by Ontario Ministry of Natural Resources Midhurst (formerly Huronia) District staff and continued annually until 1986, with the exception of 1982 when no surveys were conducted (LaFrance, 1986).

At both sites the basic survey method was a winter count of all active muskrat houses found within the respective search areas (survey zones). At Pelee the survey method covered only a portion of the entire marsh (the perimeter of all ponds along the open water-vegetation edge which is typically where muskrat house-building occurs) while at Matchedash the survey method aimed for a complete census of the entire marsh. We surveyed Pelee for muskrat houses during the winters of 2014 and 2015 and during the springs of 2017 and 2019 (four surveys spanning six years). We surveyed Matchedash for muskrat houses during the winter of 2014 and the springs of 2014-2018 (five consecutive survey years).

At Pelee we conducted surveys the first two years in winter (March 2014 and February 2015) on foot with two observers walking on the ice along the inner edge of all marsh areas (i.e., the perimeter of mapped ponds, as well as small channels and accessible pools) within each mapped survey zone, as depicted in the historic survey reports. Observers searched from the edge of the emergent vegetation to approximately $15 \mathrm{~m}$ inwards from the open water edge (or as far into the vegetation stands as we could detect muskrat houses) and counted all muskrat houses seen. This is the same survey method used in the historic surveys at Pelee, except that in some years the observers rode an ATV rather than walked. The latter two years of our surveys (2017 and 2019) were conducted by canoe, as ice conditions were not adequate in the winters of those years to allow surveyors to safely traverse the marsh. The canoe-based surveys followed the same routes covered on foot in the first two survey years, with the exception of one survey zone which was conducted on foot in chest waders as it did not contain enough open water to paddle a canoe through. When surveys were conducted by canoe, the lead observer was stationed in the bow in a kneeling position and frequently stood up to ensure a comparable search height to the surveys conducted on foot in winter. As well, spring surveys were conducted in early spring before new growth and green-up of the marsh vegetation so that visibility of muskrat houses was comparable to surveys conducted in winter.

At Matchedash we conducted the very first survey in late winter (March 2014) on a combination of foot and snowmobile with two observers covering the entire marsh (both perimeter and interior areas); however, the snow cover was very deep (over 5 feet) and we were concerned that muskrat houses might be buried and thus not detected. We verified this suspicion by returning to the site early the following spring (2 months later) and paddled the perimeter of the entire marsh by canoe, counting several muskrat houses that we missed due to snow depth in the winter. We know that these were not houses that were newly built in the interval between our winter and spring visits because we conducted the survey in May only a few weeks after ice-out which is not a time when muskrats conduct house-building in this region. Muskrats typically build houses in the fall before freeze-up and these remain in place over the winter until they start to deteriorate 
(if no longer in use) the following spring-summer (Dozier, 1948). Over the following four years (2015-2018) we conducted all surveys at this site in May by canoe as the Matchedash area typically receives heavy snow accumulation and thus we knew that detection of houses would continue to be hindered by snow cover in winter. The historic surveys, however, were conducted every year in winter by snowmobile (except for 1981 when it was conducted by boat in spring) and covered the entire marsh area, not just the perimeter of the vegetation stands which the canoe-based surveys were restricted to (even though this is where most muskrat houses typically occur). We compensated for this difference in survey coverage by using high-resolution aerial photographs of the study area (collected ourselves in March 2018 during low snow cover conditions) to count muskrat houses in the areas we could not access by canoe. We also used our aerial count of houses found in these inaccessible areas of the marsh, in combination with aerial verification of the houses found by ground survey, to calculate a percentage of the total count of houses missed by the spring ground survey (i.e. a field detection rate). We then applied that detection rate to the previous four survey years' counts as a correction factor, yielding what we feel should represent the most accurate final house count possible for each year based on all available data. In other words, for each survey year we have a minimum count of muskrat houses observed from only the early spring canoe surveys and an estimated maximum count based on a combination of the canoe and aerial surveys (the latter presumably representing greater detection accuracy). We considered the estimated maximum count as our final house count for each year.

At Pelee we also used imagery-based house counts in 2017 and 2019 to supplement our field counts in the survey areas we could not access, similar to how we handled the Matchedash data. For this we used highresolution imagery available from the County of Essex (Essex County, 2020) as well as imagery collected and shared by Point Pelee National Park. We used our final house counts (i.e. our estimated maximum counts) at both Pelee and Matchedash in all survey years to compute an average house count at each site for the contemporary survey period. Because we chose to use our estimated maximum house counts that were based on a combination of aerial and ground census methods, rather than our minimum ground-only observations (which were incomplete in some cases), we are confident that we have not underestimated the current muskrat population at either site by potential detection errors (i.e. missed houses) resulting from site conditions or incomplete survey coverage.

Historic house counts dating back to 1957 are available for Pelee, however a detailed breakdown of the count results by survey zone was not provided until 1967. Examining these data, we realized that not all areas of the marsh were surveyed consistently from year to year and that some years suffered from poor survey conditions (e.g., due to deep snow) which likely decreased house detection rates. Because we could not supplement the historic field data with imagery as we did for our recent surveys, we decided that a trend over time analysis of house counts would be more accurate if we omitted the survey years and zones where survey coverage was reportedly poor, incomplete or simply unknown due to a lack of information in historic reports. We therefore began our analysis of the Pelee muskrat population with the 1968 data and removed the years 1977-1978, as well the survey zones 14 and 15 in all years, from our final analyses to create a reduced but more consistent and comparable set of time series data. However, we also computed a mean house count for the 1968-1980 period at Pelee without excluding the two survey zones to compare with our final results. At Matchedash survey coverage was generally more consistent from year to year (with a couple minor exceptions) and thus we used all seven survey years and the annual results obtained for the entire survey area to calculate a mean house count for the historic period at that site.

As was done for the historic surveys, we used our annual counts of muskrat houses as indices of abundance for each site, a common method first described by Dozier (1948) and since undertaken by many researchers as a means to infer abundance and track annual change in muskrat populations (e.g., Greenhorn et al., 2017; Kroll and Meeks, 1985; Proulx and Gilbert, 1984; Toner et al., 2010).

\section{Results}

\subsection{Point Pelee Marsh}

We found very low numbers of muskrat houses at Pelee over our four contemporary survey years between 
2014-2019 as compared to the historic survey period from 1968-1980 (Fig. 3). The mean (SE) number of muskrat houses found at Pelee between 1968 and 1980, excluding incomplete survey zones and years, was 719 (202.9). The $95 \%$ confidence interval for house counts during these years was 267 to 1171 . In contrast, we observed a mean (SE) house count of 47 (7.4) during 2014-2019, excluding the same zones as we did with the historic data set. The $95 \%$ confidence interval for the house counts during these latter years was 24 to 71.

Our contemporary surveys of Pelee represent a 93\% decline in mean muskrat abundance from historic levels 40-50 years prior (Fig. 4). Retaining the count results for the excluded survey zones still resulted in a dramatic difference in the mean number of houses found between each survey period (791 historically vs. 80 recently) and a $90 \%$ decline in house numbers.

\subsection{Matchedash Bay-Gray Marsh}

Similar to Pelee, we found relatively low numbers of muskrat houses at Matchedash in each of our five recent survey years from 2014-2018 when compared to the historic survey period from 1979-1986 (Fig. 3). The mean (SE) number of muskrat houses found at Matchedash between 1979 and 1986 was 650 (81.9). The 95\% confidence interval for house counts averaged across these years was 450 to 850. In contrast, we observed a mean (SE) house count of 57 (9.1) during 2014-2018. The 95\% confidence interval for the house counts averaged across these latter years was 32 to 82 .

Our contemporary surveys of Matchedash represent a 91\% decline in mean muskrat abundance from historic levels 30-40 years prior (Fig. 4).

\section{Discussion}

Our surveys demonstrate substantial declines in muskrat populations at two large coastal wetlands in Ontario based on direct field observations spanning 40-50 years. The data we present are not confounded by trapper effort like harvest data often are, but they correspond to reported trends in provincial harvest data and are consistent with anecdotal evidence of muskrat decline. Ahlers and Heske (2017) called for direct evidence of muskrat population trends to avoid confounds with harvest effort, and we provide such evidence here.

It has been suggested that most survey techniques for muskrats are only feasible across small geographic extents and may not be useful for examining large-scale population trends (Roberts and Crimmins, 2010). While this may be true, we have two independent data sets from widely separated wetlands illustrating declines of similar magnitude over a similar time frame, which are also coincident with declines in our provincial harvest data over the same approximate time period. Collectively this suggests a broader trend of decline in muskrat populations across Ontario.

The greater than $90 \%$ decline in muskrat house abundance at each of our study sites is startling, yet we are confident the survey data indicate a true decline of this magnitude. In many wildlife surveys there is potential for over-estimating or under-estimating abundance as a result of observer error. In the case of muskrat house surveys, some houses may be missed, and some structures may be falsely labelled as active houses when they are in fact only feeding structures or inactive houses, or vice versa. However, we assume that in our study, on average, detection probabilities were similar from year to year (except the survey years that were deliberately eliminated from the analyses because the surveyors reported poor conditions that hindered their ability to detect houses), and that in most cases muskrat structures were correctly identified. We attempted to replicate the historic survey methods as closely as possible so that the results we obtained could be largely attributed to actual population change and not simply methodology differences. Furthermore, considering that our final house counts for each recent survey year at each site were adjusted based on imagery data that were used to supplement our field counts, and it is more difficult to distinguish new houses from old ones on air photos, it is more likely that we have over-estimated contemporary muskrat abundance by including houses in our tally that are no longer in use. Therefore, our estimates of the magnitude of muskrat population change at each site are likely conservative.

Muskrats have been shown to fluctuate periodically, thus it is possible that low house counts may be reflecting 
a low phase in a normal population cycle. Erb et al. (2000) examined ninety-one historic time series of muskrat harvest data from boreal, taiga and southern Arctic regions of Canada and found overall that mean period length ranged from 3.7 to 8.6 years. If the same pattern holds true in southern Ontario and the start of our surveys corresponded to a population low phase, we would expect to have seen a greater increase in our recent house count numbers over the five to six years we conducted the surveys. We observed no such increasing trend, and similarly, there is no increasing trend evident in muskrat harvest data collected over the same time period. Instead, it appears that muskrat populations at Point Pelee and Matchedash Bay-Gray Marsh are currently persisting at very low levels and are much reduced from the levels seen 30-50 years ago. Furthermore, harvest data suggest that these declines are widespread.

\subsection{Reasons for decline}

It is unclear whether the apparent declines in muskrat abundance that we have demonstrated are a result of a broad-scale underlying cause or site-specific factors.

In recent studies of muskrat occurrences in Lake Ontario-St. Lawrence River coastal wetlands it was found that water-level regulation of that system had a negative influence on muskrat abundance (Greenhorn et al., 2017; Toner et al., 2010). While the two Great Lakes that our study sites occur on are not subject to such tightly controlled water levels as Lake Ontario, both Lake Erie and Lake Huron have experienced record high and extended low water levels over the duration that our investigation spans (NOAA, 2020), primarily brought on by weather extremes and climate variability over the past few decades (Gronewold and Rood, 2019). The presence of water, either through excessively high water levels or periods of drought, has been considered the greatest selection pressure affecting muskrats (Bellrose and Brown, 1941; Errington, 1963; Virgl and Messier, 1996; Proulx and Gilbert, 1983; Ahlers et al., 2015; Ward and Gorelick, 2018). Essentially, the water level in a marsh is suitable for muskrats when it is deep enough to maintain travel routes and allow access to houses and feeding areas underwater, even in cold winters when ice cover can be very thick, yet shallow enough to permit the growth of emergent aquatic vegetation. It is also important for muskrats that any changes in water level occur gradually, so that houses are neither flooded out nor left high and dry. We have not conducted a detailed analysis of water level patterns at Pelee and Matchedash in relation to muskrat occupancy, therefore this is an avenue that warrants closer examination.

Closely related to water levels is the hypothesis that habitat change has led to dramatic reductions in muskrat numbers. For example, Ward and Gorelick (2018) suggested that the loss of critical wetland habitat due to drying is the primary driver responsible for the decline of muskrats in the Peace-Athabasca Delta over the past half-century and potentially across their entire native range. While the amount of wetland habitat on the landscape available to muskrats is certainly an important factor influencing their population levels, the sizes of the wetlands in our study area have not changed appreciably over the timespan of our investigation. Province-wide, Ontario has experienced significant loss of wetlands over the past two centuries, but most of this loss (70\% of original wetland area) occurred between the time of European settlement (circa late 1700s) and 1982 (Ontario Biodiversity Council, 2010). Only a relatively small additional amount of wetland area loss (3.8\%) occurred between 1982 and 2014 (Ontario Biodiversity Council, 2015). Thus, it is clear that the vast majority of wetland loss in Ontario occurred prior to the recent period of muskrat decline that we have demonstrated. Therefore, it seems unlikely that a loss of habitat area is a major factor driving the recent declines we have seen in muskrat populations in Ontario over the past 30-50 years.

A more likely factor responsible for muskrat decline in Ontario is a change in the overall quality of muskrat habitat, particularly in the structure and composition of wetlands that were previously occupied in large numbers by muskrats. Proulx and Gilbert (1983) demonstrated that muskrats prefer to occupy areas of marsh with a 1:1 interspersion of emergent vegetation and open water, a structural pattern of habitat patchiness often referred to as a "hemi-marsh". Yet there is evidence around the Great Lakes basin that the structural diversity of wetlands has declined. The research of Wilcox et al. (2008) has shown that Lake Ontario coastal wetlands have experienced a significant decrease in emergent marsh habitat heterogeneity and the amount of emergent-open water edge in the past 50 years since regional water level control was implemented. At the Point Pelee Marsh, one of our two study sites, Markle et al. (2018) demonstrated that both marsh 
habitat diversity and open water connectivity have declined since 1931, with the most significant reductions occurring between 1959 and 2015. Similarly, at our other study site, the Matchedash Bay-Gray Marsh, air photo interpretations by Taylor et al. (2015) demonstrate a large increase in the areal coverage of dense emergent vegetation along with a correspondingly large decrease in the extent of aquatic habitat between the years of 1973 and 2008. These reductions in habitat structural quality coincide with the time periods over which we have demonstrated a decline in muskrat abundance at both sites.

The research of Markle et al. (2018), Wilcox et al. (2008) and others (e.g., Farrell et al., 2010, Wilcox et al., 2003) also demonstrate changes to the compositional quality of Great Lakes coastal wetlands over the past 50 years that coincide with the decline in muskrats that we report here. Not only have they demonstrated class-level habitat changes, such as the expansion of dense emergent cattail marshes at the expense of meadow marsh and other shallow mixed marsh communities, but they have documented dramatic increases in the prevalence of invasive emergent marsh species such Phragmites australis subsp. australis, Typha angustifolia and Typha $X$ glauca . In particular, the hybrid species of cattail (Typha $X$ glauca) has increased significantly in extent, displacing both the native broad-leaved cattail (Typha latifolia) and other aquatic plant species, and is now the dominant emergent species in most of our coastal wetlands. How such changes in both the structure and composition of coastal wetlands may be driving muskrat decline is a question that deserves further exploration.

Several other explanations for the decline in muskrat populations are possible but seem less likely for a variety of reasons. Overharvest by trappers is often postulated as the reason behind furbearer population declines, however the demographic characteristics of muskrats makes them resilient to overharvest (Boutin and Birkenholz, 1987). Even when heavy harvest does occur in a wetland, the muskrat's high reproductive output and dispersal ability usually enables a population to rebound relatively fast. As well, one of our study sites (Pelee) has been closed to muskrat trapping since 1959, therefore muskrat harvest levels have had no direct influence on the population dynamics there for at least 50 years. At our other study site, local long-time trappers have reported low harvests and great difficulty finding muskrats for many years now (M. Dunlop, personal communication, March 2014).

Predation and disease are important natural aspects of muskrat ecology that can affect their abundance over the short-term, but which typically balance out over the long-term. Errington (1963) suggested that significant mortality of muskrats due to predation usually only occurs when muskrats are already vulnerable as a result of disease or habitat changes such as loss of cover, drought/flooding, or freeze-outs. As well, muskrat populations typically respond to predation mortality by a variety of compensatory processes, such as increased reproduction and survival among the remaining individuals (Errington, 1951). Mink (Neovison vison ) are considered the most important predator of muskrats (McDonnell, 1983), but there is evidence from harvest data of long-term mink population decline in Ontario (Gorman, 2007) and no evidence of local mink population booms at our sites (personal observations). Disease outbreaks among muskrats are typically localized and usually occur when a muskrat population is under some form of stress, such as overcrowding, food shortage or drought (Errington, 1963). Also, as with predation, the effects of disease on muskrat population size are often short-term because of compensatory responses in other sources of mortality or in reproduction. We are unaware of any documented outbreaks of disease in muskrats at either of our study sites or elsewhere in Ontario over the time period that our study covers (Ganoe et al., 2020).

\subsection{Implications of muskrat decline}

A marked decline in muskrat populations is concerning not only for the value of muskrats in their own right, but also for the broader economic, ecological, and cultural benefits that muskrats and wetlands provide. Muskrats are highly valued by trappers and an important part of our natural heritage. In many Indigenous cultures the muskrat is revered for the life-giving role it is said to have played in the creation of the Earth as we know it. As such, a loss of muskrats comes with costs, many of which we might already be experiencing (Papworth et al., 2008).

Muskrats manipulate marshes (Higgins and Mitsch, 2001), promoting greater diversity and providing ecolo- 
gical services to humans and other wetland species. Many of the species that benefit from muskrats are of conservation concern themselves. Thus, the loss of muskrats from our wetlands may compound existing problems within these wetlands and across broader landscapes containing wetlands. Understanding the current state of the muskrat might help us to better understand the current state of our wetland ecosystems.

There is a clear need for more research on the relationship between muskrat populations and the various factors that influence their abundance, especially if we are to understand what has led to their recent declines and if we wish to prevent further loss of this iconic species.

\section{Acknowledgements}

We gratefully acknowledge the assistance and marsh access provided to us by the staff of Point Pelee National Park and Steve Zeidler of Matchedash Camp, as well as Ministry of Natural Resources and Forestry Midhurst District office staff. We thank the following individuals for their technical support, advice and tireless efforts in the field in search of muskrat houses: M. Allan, L. Brown, M. Brown, T. DeGazio, T. Dobbie, J. Greenhorn, S. Hagey, G. Meadows, S. Morin, S. Newar, H. Sawada, L. Scott, B. Stevenson and K. Wisniewski. Financial support for this study was provided by the Ontario Ministry of Natural Resources and Forestry; in-kind support was provided by Parks Canada (Point Pelee National Park).

\section{Data Accessibility Statement}

Data are archived in the Dryad data repository at: https://doi.org/10.5061/dryad.xxxxxxxx

\section{References}

Ahlers, A.A., Cotner, L.A., Wolff, P.J., Mitchell, M.A., Heske, E.J., Schooley, R.L., 2015. Summer precipitation predicts spatial distributions of semiaquatic mammals. PLoS One 10, 1-14. https://doi.org/10.1371/journal.pone.0135036

Ahlers, A.A., Heske, E.J., 2017. Empirical evidence for declines in muskrat populations across the United States. Journal of Wildlife Management 81, 1408-1416. https://doi.org/10.1002/jwmg.21328

Albert, D.A., Wilcox, D.A., Ingram, J.W., Thompson, T.A., 2005. Hydrogeomorphic classification for Great Lakes coastal wetlands. Journal of Great Lakes Research 31, 129-146. https://doi.org/10.1016/S03801330(05)70294-X

Bailey, T.N., 1981. Factors influencing furbearer populations and harvest on the Kenai National Moose Range, Alaska. Pp. 249-272, in J.A. Chapman and D. Pursley (Eds.). Proceedings of the Worldwide Furbearer Conference. International Fur Trade Federation, Maryland Fur-trappers Association. Frostburg, MD.

Bellrose, F.C., Brown, L.G., 1941. The effect of fluctuating water levels on the muskrat population of the Illinois River Valley. Journal of Wildlife Management 5, 206. https://doi.org/10.2307/3795587

Benoit, L.K., Askins, R.A. 1999. Impact of the spread of Phragmites on the distribution of birds in Connecticut tidal marshes. Wetlands 19 (1), 194-208. https://doi.org/10.1007/BF03161749

Boutin, S., and D.E. Birkenholz, 1987. Muskrat and Round-tailed Muskrat. Pp. 315-325, in M. Novak, J.A. Baker, M.E. Obbard, and B. Malloch (Eds.), Wild Furbearer Management and Conservation in North America. Ontario Ministry of Natural Resources, Toronto.

Bremner, H. and D. Reive, 1980. Winter Muskrat Survey, February 1980. Resource Conservation Section, Point Pelee National Park, Ontario. Parks Canada. 9 pp.

Brietzke, C., 2015. Muskrat ecology in the Mackenzie Delta: Insights from local knowledge and ecological field surveys. Arctic 68, 527-531. https://doi.org/10.14430/arctic4538

Bulmer, M.G. 1974. A statistical analysis of the 10-year cyle in Canada. Journal of Animal Ecology 43, 701-718. https://doi.org/10.2307/3532 
Clark, W.R., 1994. Habitat selection by muskrats in experimental marshes undergoing succession. Canadian Journal of Zoology 72, 675-680. https://doi.org/10.1139/z94-091

Clark, W.R., Kroeker, D.W., 1993. Population dynamics of muskrats in experimental marshes at Delta, Manitoba. Canadian Journal of Zoology 71, 1620-1628. https://doi.org/10.1139/z93-228

Connors, L.M., Kiviat, E.., Groffman, P.M., Ostfeld, R.S., 2000. Muskrat (Ondatra zibethicus ) disturbance to vegetation and potential net nitrogen mineralization and nitrification rates in a freshwater tidal marsh. American Midland Naturalist 143(1), 53-63. https://doi.org/10.1674/00030031(2000)143[0053:MOZDTV]2.0.CO;2

Crins, W.J., Gray, P.A., Uhlig, P.W.C. and Wester, M.C., 2009. The Ecosystems of Ontario, Part I: Ecozones and Ecoregions. Ontario Ministry of Natural Resources, Peterborough Ontario, Inventory, Monitoring and Assessment, SIB TER IMA TR- 01, $71 \mathrm{pp}$.

De Szalay, F.A., Cassidy, W., 2001. Effects of muskrat (Ondatra zibethicus ) lodge construction on invertebrate communities in a Great Lakes coastal wetland. American Midland Naturalist 146, 300-310. https://doi.org/10.1674/0003-0031(2001)146[0300:eomozl]2.0.co;2

Diggins, T.P., Stewart, K.M., 2000. Evidence of large change in unionid mussel abundance from selective muskrat predation, as inferred by shell remains left on shore. International Review of Hydrobiology 85, 505-520. https://doi.org/10.1002/1522-2632(200008)85:4<505::aid-iroh505>3.3.co;2-n

Dozier, H.L., 1948. Estimating muskrat populations by house counts. Transactions of the North American Wildlife and Natural Resources Conference 13, 372-389.

Ducks Unlimited, 2011. Eastern Habitat Joint Venture Flagship Project, North American Waterfowl Management Plan. Matchedash Bay Overview, Nov. 2011 project tour notes. 3 pp.

Erb, J., Stenset, N.C., Boyce, M.S., 2000. Geographic variation in population cycles of Canadian muskrats (Ondatra zibethicus ). Canadian Journal of Zoology 78, 1009-1016. https://doi.org/10.1139/z00-027

Erb, J., Perry, H.R., 2003. Muskrats. Pp. 311-348 in G.A. Feldhamer, B.C. Thompson, and J.A. Chapman (Eds.). Wild Mammals of North America: Biology, Management, and Conservation. Johns Hopkins University Press, Baltimore, MD.

Errington, P.L., 1951. Concerning fluctuations in populations of the prolific and widely distributed muskrat. The American Naturalist 85, 273-292. https://www.journals.uchicago.edu/doi/10.1086/281680

Errington, P.L., 1963. Muskrat Populations. Iowa State University Press. Ames, Iowa. 665 pp.

Errington, P.L; Siglin, R.J.; Clark, R.C., 1963. The decline of a muskrat population. Journal of Wildlife Management. 27(1), 1-8. https://doi.org/10.2307/3797774

County of Essex, 2020. Essex County Open Data - Aerial Imagery Rest Services. https://opendata.countyofessex.ca/pages/imagery.

Farrell, J.M., Murry, B.A., Leopold, D.J., Halpern, A., Rippke, M., Godwin, K.S., Hafner, S.D., 2010. Waterlevel regulation and coastal wetland vegetation in the upper St. Lawrence River: inferences from historical aerial imagery, seed banks, and Typha dynamics. Hydrobiologia 647, 127-144. https://doi.org/10.1007/s10750009-0035-z

Fur Institute of Canada, 2019. Canada's Fur Trade: Facts and Figures. https://fur.ca/fur-trade/canadas-furtrade-fact-figures/. Accessed April 2020.

Gartner Lee Limited, 1990. A Biological Inventory and Evaluation of the Matchedash Bay Provincial Wildlife Area. Fish and Willdlife, Huronia District and Parks and Recreational Areas Section, Central Region. Ontario Ministry of Natural Resources, Aurora, Ontario. 117 pp. 
Ganoe, L.S., Brown, J.D., Yabsley, M.J., Lovallo, M.J., Walter, W.D., 2020. A Review of pathogens, diseases, and contaminants of muskrats (Ondatra zibethicus) in North America. Frontiers in Veterinary Science 7, 1-13. https://doi.org/10.3389/fvets.2020.00233

Gorman, R., 2007. Spatial analysis of population trend of American mink (Neovison vison ) in Ontario. Master's Thesis, Trent University, Peterborough, Canada.

Greenhorn, J.E., Sadowski, C., Holden, J., Bowman, J., 2017. Coastal wetlands connected to Lake Ontario have reduced muskrat (Ondatra zibethicus ) abundance. Wetlands 37, 339-349. https://doi.org/10.1007/s13157016-0874-0

Gregory, G.J., Dibblee, R., Daoust, P., Van, M.R., Heuvel, D.E.N., 2019. Declines in muskrat (Ondatra zibethicus ) population density in Prince Edward Island, Canada. Canadian Widlife Biology and Management $8(2), 46-60$.

Gronewold, A.D., Rood, R.B., 2019. Recent water level changes across Earth's largest lake system and implications for future variability. Journal of Great Lakes Research. 45, 1-3. https://doi.org/10.1016/j.jglr.2018.10.012

Hickey, J.M., Malecki, R.A., 1997. Nest site selection of the black tern in Western New York. Colonial Waterbirds 20, 582-595. https://doi.org/10.2307/1521614

Higgins, C., and Mitsch, W.J., 2001. The role of muskrats (Ondatra zibethicus) as ecosystem engineers in created freshwater marshes. Pp. 81-86 in Annual Report of the Olentangy River Wetland Research Park. http://hdl.handle.net/1811/358

Kiviat, E. 1978. Vertebrate use of muskrat lodges and burrows. Estuaries 1, 196-200. https://doi.org/10.2307/1351464

Kaminski, R.A., Prince, H.H., 1981. Dabbling duck and aquatic macroinvertebrate responses to manipulated wetland habitat. Journal of Wildlife Management 45, 1-15. https://doi.org/10.2307/3807868

Keddy, P.A., 2010. Herbivory (Ch. 6), p. 162 in Wetland Ecology: Principles and Conservation, $2^{\text {nd }}$ ed. Cambridge University Press, New York.

Kroll, R.W., Meeks, R.L., 1985. Muskrat population recovery following habitat re-establishment near southwestern Lake Erie. Wildlife Society Bulletin 13, 483-486. https://www.jstor.org/stable/3782675

LaFrance, W. 1986. Muskrat House Survey Matchedash Bay and Gray Marsh. Huronia District, Ontario Ministry of Natural Resources, Canada. 13 pp.

Landholt, L.M., Genoways, H.H., 2000. Population trends in furbearers in Nebraska. Transactions of the Nebraska Academy of Sciences, 2000, p. 97. https://digitalcommons.unl.edu/tnas/54

Litzgus, J.D., Brooks, R.J., 2000. Habitat and and temperature selection of Clemmys guttata in a northern population. Journal of Herpetology 34, 178-185. https://doi.org/10.2307/1565413

MacGregor, D., 2013. Teachings from the Muskrat. Muskrat Magazine.com. http://muskratmagazine.com/teachings-from-the-muskrat/. Accessed March 2020.

Markle, C.E., Chow-Fraser, G., Chow-Fraser, P., 2018. Long-term habitat changes in a protected area: Implications for herpetofauna habitat management and restoration. PLoSONE 13(2), e0192134. https://doi.org/10.1371/journal.pone.0192134

McDonnell, J.A., 1983. The Muskrat. Ontario Ministry of Natural Resources. Toronto, Canada. 18 pp.

Menefy, R., 1969. Muskrat Study, Point Pelee National Park, Summer 1969. Parks Canada. 79 pp.

Messier, F., Virgl, J.A., 1992. Differential use of bank burrows and lodges by muskrats, Ondatra zibethicus, in a northern marsh environment. Canadian Journal of Zoology 70, 1180-1184. https://doi.org/10.1139/z92-165 
MNRF, 2015. LIO Wetland Data Class (Ontario wetland shapefiles). Mapping and Information Resources Branch, Ontario Ministry of Natural Resources and Forestry. Her Majesty the Queen in right of Ontario. https://geohub.lio.gov.on.ca/datasets/mnrf::wetlands

NOAA - Great Lakes Environmental Research Laboratory, 2020. Great Lakes Water Level Observations:https://www.glerl.noaa.gov/data/wlevels/levels.html\#observations.Accessed August 2020.

Nummi, P., Väänänen, V.M., Malinen, J., 2006. Alien grazing: Indirect effects of muskrats on invertebrates. Biological Invasions 8, 993-999.

https://doi.org/10.1007/s10530-005-1197-x

Nyman, J.A., Chabreck, R.H., Kinler, N.W. 1993. Some effects of herbivory and thirty years of weir management on emergent vegetation in a brackish marsh. Wetlands 13, 165-175. https://doi.org/10.1007/BF03160877

Obbard, M.E., Jones, J.G., Newman, R., Booth, A., Satterthwaite, A.J., Linscombe, G., 1987. Furbearer Harvests in North America. Pp. 1007-1034 (Ch. 64) in M. Novak, J.A. Baker, M.E. Obbard, and B. Malloch (Eds.), Wild Furbearer Management and Conservation in North America. Ontario Ministry of Natural Resources, Toronto.

OFMF, 2019. Types of Furbearers: muskrat. Ontario Fur Managers Federation. https://furmanagers.com/muskrat/. Accessed November 2019.

Ontario Biodiversity Council, 2015. State of Ontario's Biodiversity 2015: Summary. A report of the Ontario Biodiversity Council, Peterborough, ON.

Ontario Biodiversity Council, 2010. State of Ontario's biodiversity 2010-highlights report. A report of the Ontario Biodiversity Council, Peterborough, ON.

Papworth, S.K., Rist, J., Coad, L., Milner-Gulland, E.J., 2008. Evidence for shifting baseline syndrome in conservation. Conservation Letters 2(2), 93-100. https://doi.org/10.1111/j.1755-263X.2009.00049.x

Parks Canada, 2010. Point Pelee National Park of Canada Management Plan. June 2010. Her Majesty the Queen in right of Canada.

Proulx, G, Gilbert, F.F., 1983. The ecology of the muskrat, Ondatra zibethicus, at Luther Marsh, Ontario. Canadian Field-Naturalist 97, 377-390.

Proulx, G., Gilbert, F.F., 1984. Estimating muskrat population trends by house counts. Journal of Wildlife Management 48, 917-922. https://doi.org/10.2307/3801438

Reive, D., 1978. Winter Muskrat Survey, January/February 1980. Resource Conservation Section, Point Pelee National Park, Ontario. Parks Canada. 8 pp.

Reive, D., 1979. Winter Muskrat Survey, January 1979. Resource conservation section, Point Pelee National Park, Ontario. Parks Canada. 10 pp.

Roberts, N.M., Crimmins, S.M., 2010. Do trends in muskrat harvest indicate widespread population declines? Northeastern Naturalist. 17, 229-238. https://doi.org/10.1656/045.017.0206

Scognamillo, D.G., Chamberlain, M.J. 2006. Forecasting models for harvest of River Otter in Louisiana. Proceedings of the Southeastern Association of Fish and Wildlife Agencies 60, 25-32.

Statistics Canada, 2011. Fur Statistics 2010. Catalogue no. 23-013-X, vol. 8. Statistics Canada, Agriculture Division, Ottawa.

Straka, J.R., Antoine, A., Bruno, R., Campbell, D., Campbell, Ron, Campbell, Ross, Cardina, J., Gibot, G., Gray, Q.Z., Irwin, S., Kindopp, R., Ladouceur, R., Ladouceur, W., Lankshear, J., Maclean, B., Macmillan, S., Marcel, F., Marten, G., Marten, L., McKinnon, J., Patterson, L.D., Voyageur, C., Voyageur, M., Whiteknife, 
G. "Sloan", Wiltzen, L., 2018. We used to say rats fell from the sky after a flood: Temporary recovery of muskrat following ice jams in the peace-athabasca delta. Arctic 71, 218-228. https://doi.org/10.14430/arctic4714

Toner, J., Farrell, J.M., Mead, J. V., 2010. Muskrat abundance responses to water level regulation within freshwater coastal wetlands. Wetlands 30, 211-219. https://doi.org/10.1007/s13157-010-0034-x

Virgl, J.A., Messier, F., 1996. Population structure, distribution, and demography of muskrats during the ice-free period under contrasting water fluctuations. Ecoscience 3, 54-62. https://doi.org/10.1080/11956860.1996.11682315

Wainscott, V.J., Bartley, C., Kangas, P., 1990. Effect of muskrat mounds on microbial density on plant litter. American Midland Naturalist 123, 399-401. https://doi.org/10.2307/2426568

Ward, E.M., Gorelick, S.M., 2018. Drying drives decline in muskrat population in the Peace-Athabasca Delta, Canada. Environmental Research Letters. 13 124026. https://doi.org/10.1088/1748-9326/aaf0ec

Weller, M.W., Fredrickson, L.H., 1973. Avian ecology of a managed glacial marsh. Living Bird 12: 269-291.

White, H.B., Decker, T., O’Brien, M.J., Organ, J.F., Roberts, N.M., 2015. Trapping and furbearer management in North American wildlife conservation. International Journal of Environmental Studies 72, 756-769. https://doi.org/10.1080/00207233.2015.1019297

Wilson, W.G., Cheskey, E.D., 2001. Matchedash Bay Important Bird Area Conservation Action Plan. Canadian Nature Federation, Bird Studies Canada, Federation of Ontario Naturalists. 28 pp.

Wilcox, K.L., Petrie, S.A., Maynard, L.A., Meyer, S.W., 2003. Historical distribution and abundance of Phragmites australis at Long Point, Lake Erie, Ontario. Journal of Great Lakes Research 29, 664-680. https://doi.org/10.1016/S0380-1330(03)70469-9

Wilcox, D.A., Kowalski, K.P., Hoare H.L., Carlson, M.L., Morgan, H.N., 2008. Cattail invasion of sedge/grass meadows in Lake Ontario: photointerpretation analysis of sixteen wetlands over five decades. Journal of Great Lakes Research 34, 301-323. https://doi.org/10.3394/0380-1330(2008)34[301:CIOGMI]2.0.CO;2

Wilcox, D.A. and Meeker, J.E., 1992. Implications for faunal habitat related to altered macrophyte structure in regulated lake in northern Minnesota. Wetlands 12, 192-203. https://doi.org/10.1007/BF03160609.

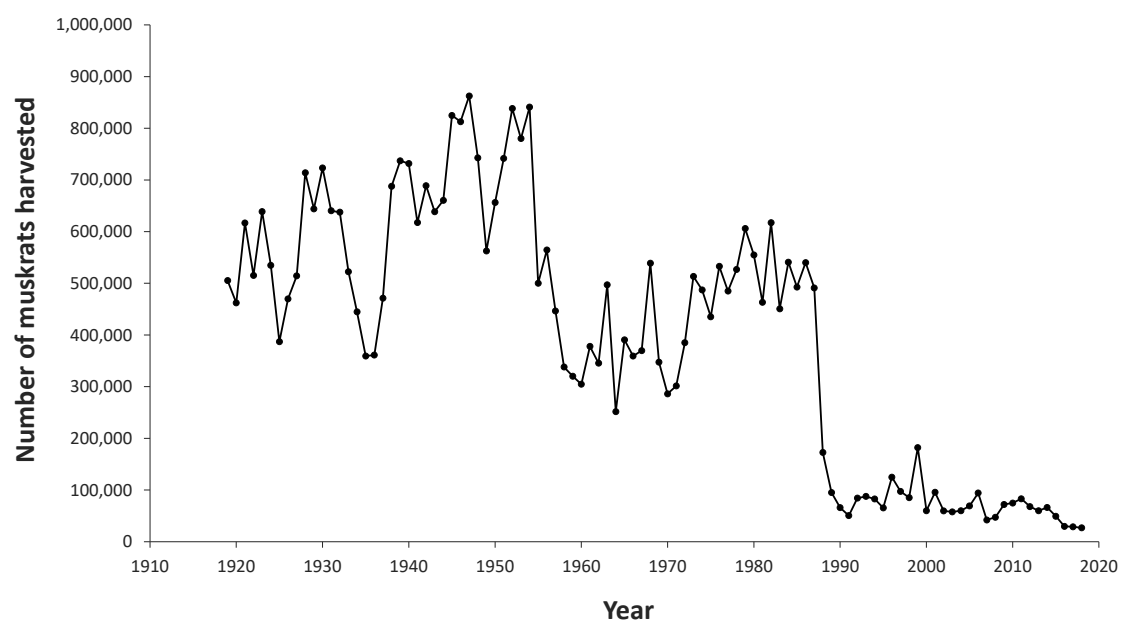



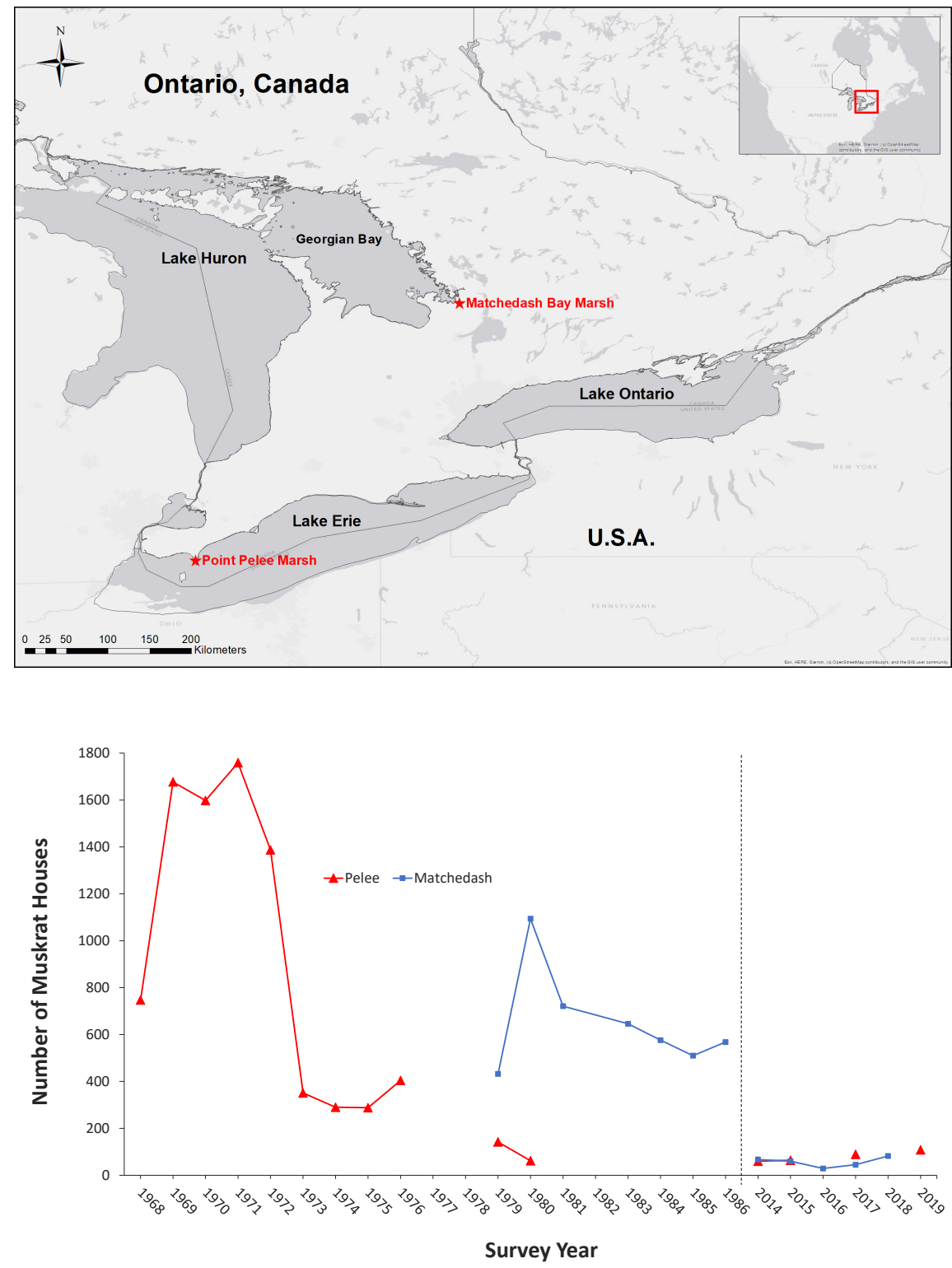

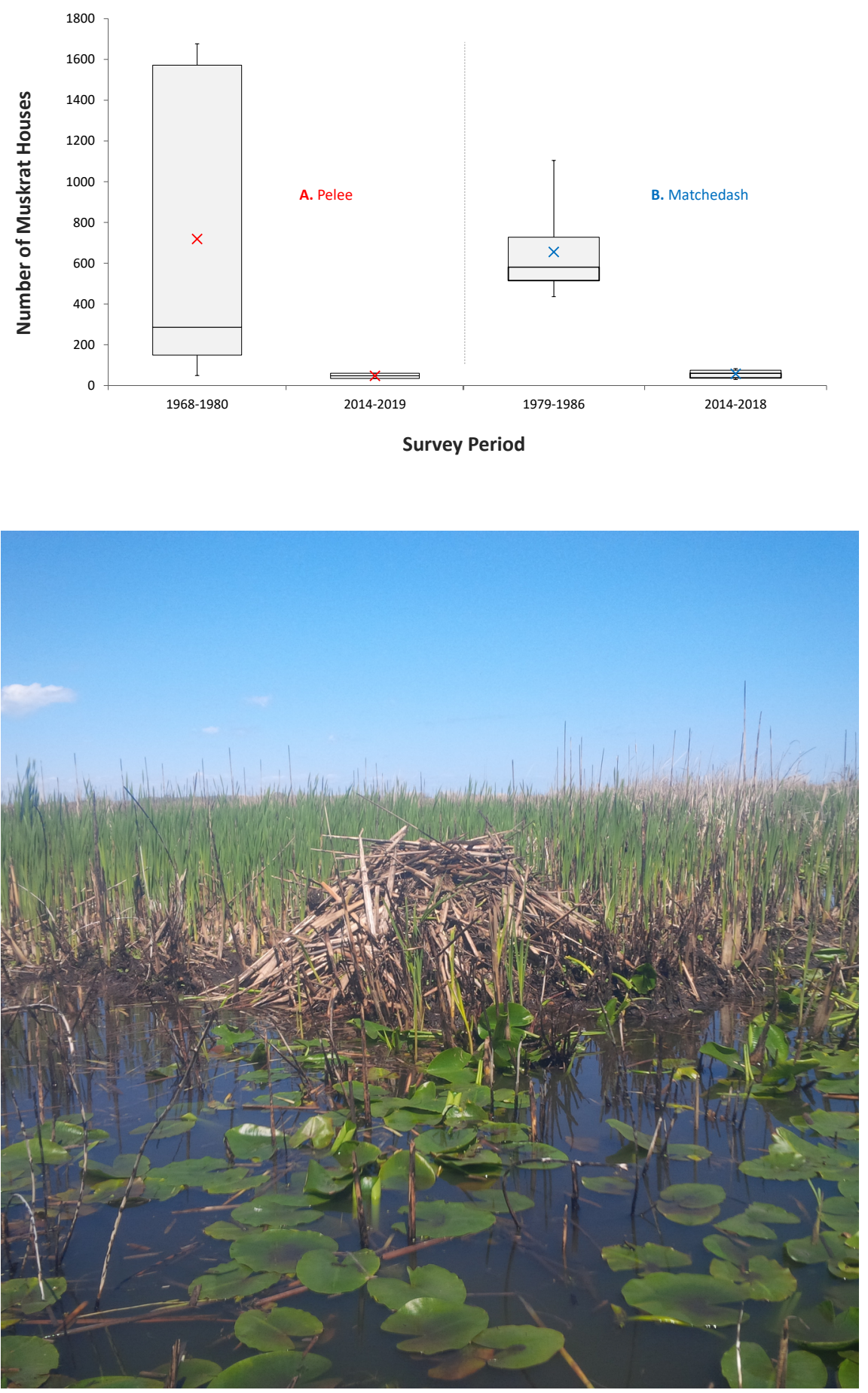